\title{
Beyond Bioproductivity: Engaging Local Perspectives in Land Degradation Monitoring and Assessment
}

Stefanie Herrmann ${ }^{1 *}$, Abdoul Aziz Diouf², Ibrahima Sall ${ }^{1}$

(1) The University of Arizona, 1064 E Lowell St, Tucson, AZ 85719, USA

(2) Centre de Suivi Ecologique, Fann Résidence, Dakar, Senegal

*Corresponding author : stef@email.arizona.edu

Short running title: Local perspectives in land degradation monitoring and assessment

Acknowledgements: This pilot project was funded by a Faculty Seed Grant by the Office of Research and Development at the University of Arizona. We thank Dr. Kamel Didan and MarieBlanche Roudaut for their helpful comments on the manuscript.

\begin{abstract}
Land degradation monitoring and assessment in the Sahel zone takes advantage of and relies substantially on temporal trends of remote sensing-based vegetation indices, which are proxies for the bioproductivity of the land. However, prior studies have shown that negative or positive trends in bioproductivity are not necessarily associated with degradation or improvement of land condition. We argue that remote sensing-based indices, while having contributed much to dismantling an outdated desertification narrative, are themselves falling short of capturing the whole picture and need to be accompanied by field observations that are relevant to local land users. We used the participatory photo elicitation method in three sites in order to elicit local pastoralists' perspectives on land degradation and identify the indicators that they use to characterize pasture quality, while empowering them to lead the discussion. The discussion revealed indicators far beyond bioproductivity, including livestock performance as well as composition and quality of the herbaceous and woody vegetative cover, invasive species, soil quality and water availability. We found that the pastoralists' interest, knowledge and field observations could potentially be harnessed using a crowd-sourcing approach in order to produce a geospatially explicit dataset of land degradation, which would be complementary to the remote sensing-based maps of trends in bioproductivity and could serve as a reference for the development of more targeted remote sensing-based indicators of land degradation.
\end{abstract}

Key words: land degradation; participatory methods; photo elicitation; Sahel; local knowledge; remote sensing 


\section{Introduction}

Land degradation - the loss of the productive potential of the land - is a serious concern in drylands, in particular for land resource-based societies such as pastoralists. It features prominently in major global institutions and initiatives, such as the United Nations Convention for Desertification (UNCCD), the United Nations Convention for Biodiversity (UNCBD), the Kyoto Protocol, and the Sustainable Development Goals (SGD).

A myriad of definitions of land degradation have been put forward, and the issue has been examined in various ways by biophysical scientists, social scientists, economists, political scientists, each putting emphasis on different aspects (Warren, 2002). As a result, estimates of the extent and severity of land degradation have varied substantially (Yengoh et al., 2015), particularly at regional to global scales. This is not surprising, as land degradation is a very context-dependent phenomenon and occurs at fine spatial scales (Warren, 2002). It has (also) been argued that its scientific basis, particularly in the case of desertification (land degradation in drylands), is so weak that the concept of desertification has ceased to be analytically useful (Thomas and Middleton, 1994; Behnke and Mortimore, 2016).

Particularly in the West African Sahel, once considered a hotspot of desertification and at the center of political and scientific debate (Hutchinson et al., 2005), new scientific knowledge has effectively dismantled the prevailing understanding of desertification (Behnke and Mortimore, 2016), with serious reservations about the standard narrative emerging as early as the late 1980s (Mortimore, 1989). A number of new developments in different fields (climate science, rangeland ecology, economic and policy frameworks) came together to make this paradigm shift possible (Herrmann and Hutchinson, 2005). Of particular importance in this context were findings of a "greening Sahel" derived from time series of satellite imagery (Eklundh and Olsson, 2003), and a changing understanding of the role of local peasants and pastoralists in land degradation. Once widely and unquestionably assumed as both perpetrators and victims of land degradation, local land users have come to be seen as rather adaptive and resilient stewards of their environments (Niamir Fuller, 1998), as appreciation of local knowledge systems has increased across the science and policy communities (Nakashima, 2015).

Local ecological knowledge, and related concepts of traditional or indigenous ecological knowledge, are not new concepts, but have received increasing interest and visibility since the pioneering work of Robert Chambers using innovative and creative approaches of Participatory Rural Appraisal (Chambers, 1994). The continuum of stakeholder participation ranges from the role of local participants as mere data providers on one end to their collaboration in defining and re-defining research questions on the other (Chouinard and Milley, 2018). Sustainability science in particular recognizes the complexity of social-ecological systems and the limitations of conventional science and management in governing them, hence calls for an approach of knowledge co-production to better address the environmental challenges of the $21^{\text {st }}$ century (Berkes, 2017). 
Yet, the views and perspectives of local pastoralists are still largely left out from assessments of rangeland degradation, even though local land users are meant to be the ultimate beneficiaries of an improved understanding of rangeland dynamics and of the management interventions enabled by it. Rather, the top down approach of remote sensing, and in particular the Normalized Difference Vegetation Index (NDVI), has been relied upon for the bulk of assessments (Bai et al., 2008; Yengoh et al., 2015), including those linked to disbursement of aid funds (GEF IEO, 2016; UNEP, 2016). While remote sensing has proven a highly useful tool that has contributed much to dismantling an outdated desertification narrative, it is not without shortfalls when it comes to a concept as complex and context-dependent as land degradation. Thus, if used as a stand-alone tool, remote sensing risks giving rise to new orthodoxies (Herrmann and Sop, 2016).

\section{The challenge of mapping degradation}

In order to support policy and interventions for food security, poverty alleviation and resource conservation, up-to-date quantitative and spatially explicit information on the occurrence and severity of land degradation is needed. Mapping land degradation has evolved from relying on expert opinion and spatially extrapolating from anecdotal evidence (Middleton and Thomas, 1992; Oldeman et al., 1991; Sonneveld and Dent, 2009) to using systematic remote sensing observations to derive long term trends in bioproductivity (Bai et al., 2008; Yengoh et al., 2015; Cherlet et al., 2018). Using coarse resolution remote sensing time series to make inferences about land degradation dates back to Tucker et al. (1991), who carried out the first analysis that refuted the idea of widespread desertification in the Sahel by showing the magnitude of interannual variations of the Normalized Difference Vegetation Index (NDVI). The NDVI is an index combining spectral reflectances in the red and near infrared region of the electromagnetic spectrum, which is highly correlated with photosynthetic activity and green biomass and can therefore be used as a proxy for bioproductivity. However, it does not directly measure a particular physical property of the vegetation cover (Myneni et al., 1995). Many more, and increasingly complex, studies based on the NDVI and its derivatives followed, all of which pointed to a greening of the Sahel region since the beginning of the NOAA AVHRR satellite record in the early 1980s (Eklundh and Olsson, 2003; Herrmann et al., 2005; Brandt et al., 2014).

Thus, if land degradation is defined simply as a long term decline in bioproductivity, remote sensing evidence indeed indicates no degradation but rather an improvement in land condition across most of the Sahel. However, land degradation reflects a complex interplay of biophysical and socioeconomic processes, which a simple remote sensing-based index cannot reproduce. A comparison of maps of NDVI trends with people's perceptions of their changing environment have shown that the greening trend is only partly associated with a perceived improvement in rangeland conditions, whereas some undesired ecological trends, such as changes in vegetation composition, fly under the radar of such broad-brush remote sensing assessments (Herrmann et al., 2014). This discrepancy calls for alternative datasets of field-based degradation indicators that are relevant to local land users, in order to complement and add local context to remote sensing-derived indicators of degradation. 


\section{Scientific vs. local ecological knowledge}

The lack of spatially explicit field observations over large areas is currently a weak link, which has hindered progress on the validation of remote sensing indicators of land degradation and on the analysis of its driving forces and impacts. Extensive field data collection by scientists is expensive and time consuming, thus the presence of scientists in the field inevitably has to remain limited in space and time. On the positive side, scientific data is systemically sampled, often quality controlled, and ready for statistical analysis. In Senegal, the Centre de Suivi Ecologique (CSE) has been carrying out ecological field campaigns since 1987, with the goal of assessing variables such as plant species composition, plant height, plant density and cover, woody leaf mass, herbaceous mass, and others (Diouf et al., 2015).

On the other hand, scientists are not the only possible source of scientifically valuable data and information (Enquist et al., 2017). Local land users, while not scientifically educated, often have accumulated a vast knowledge of their environment which, unlike that of scientists, benefits from their continuous and long term presence in the region. Their environmental observations are informal, typically not systematic, lack quality control and can be biased (Reed et al., 2013). Yet, some of these shortcomings can be overcome, and some bias with respect to what is relevant to local land users can be exploited as a positive.

Knowledge co-production, the collaborative process of bringing different knowledge sources together, is being increasingly promoted to help overcome the inadequacy of conventional science and management in an age of rapid global change and uncertainty (Berkes, 2017). Knowledge co-production approaches are beginning to be implemented in different regions of the world and make use of both indigenous and western local knowledge. In Alaska, an indigenous evidence base for ice seal and walrus habitation conservation was built by documenting the knowledge of local expert seal and walrus hunters of habitat use and drivers of change, and conservation policy goals were formulated (Gadamus et al., 2015). Woods and Ruyle (2015) documented informal monitoring used by ranchers in the US Southwest and found it generally compatible with and highly complementary to natural science and of interest to formal conservation planning. Likewise, Oba (2012) found that East African pastoralists have developed an in-depth knowledge of landscape classification using diverse environmental indicators, which is compatible with scientific ecological knowledge and can be used to assess landscape grazing potential.

Given the documented validity of local environmental knowledge, a systematic collection of this knowledge could form the basis for an alternative geospatial representation of land degradation. Not only would such a dataset of land degradation be valuable in its own right, it would also be an asset as a reference for remote sensing-derived estimates of land degradation and, coanalyzed with remote sensing data, could refine our understanding of land degradation and support the development of remote sensing-based environmental knowledge that is more locally relevant. 


\section{Tapping into local knowledge: a pilot study in the Senegalese Ferlo region}

\subsection{Study site}

We carried out a pilot study in the Senegalese Ferlo region in December of 2016 to develop evidence of pastoralists' local ecological knowledge relevant to land degradation as well as assess the potential for harnessing this knowledge more systematically. The Ferlo is considered the heart of Senegal's pastoral zone and is representative of the Sahelian climatic zone with its short, irregular rainy season (mean annual rainfall: $300-500 \mathrm{~mm}$ ), a mix of herbaceous vegetation and scattered shrubs and trees, and only marginal dry farming potential (Tappan et al., 2004). The region is sensitive to drought impacts and primarily used for grazing.

We selected three sites in the vicinity of the town of Linguère that represent the diversity of landscapes in the Ferlo (Fig.1): (1) Barkedji in the Southern Sandy Pastoral Region, (2) Yangyang in the Northern Sandy Pastoral Region, and (3) Dodji in the Ferruginous Pastoral Region. Each site consists of a mainly pastoral community that has developed around a borehole. In each site, with the help of local facilitators, we assembled a focus group of 4 to 10 pastoralists who had been residents of the area for a long time and were considered among the most knowledgeable of pastoralist issues and the environment.

\subsection{Photo elicitation}

The core of our participatory research approach in working with the pastoralists was the photo elicitation method. Photo elicitation is a qualitative research method that empowers participants to document and share their perspective by capturing their observations in photographs and explain the meanings of the photographs in subsequent discussions (Collier, 1957; Collier and Collier, 1986). These visuals and accompanying narratives give researchers access to the participants' worldview and potentially a deeper understanding and appreciation of their knowledge. While the method hails from the behavioral sciences, it has recently also been employed in the participatory evaluation of land management, where it was found to enhance the information gathered in semi-structured interviews (Kong et al., 2015).

In the context of this pilot study, we used the photo elicitation method to give a voice to the pastoralists as the experts on their environment based on their long presence in the region and intimate familiarity with their natural surroundings, in particular with the pasture conditions. In each of the three focus groups, an initial visit introduced the background and goals of our pilot study - to learn about their environmental concerns and their way of diagnosing or attributing land degradation -, garnered the pastoralists' interest in participating, and instructed participants in the use of and what to document with the camera that was left with them.

A second visit, the actual photo elicitation, took place 2-3 days after the first and gave participants the opportunity to show and explain the photos they had taken (Fig. 2), which were projected onto a wall where electricity was available or otherwise displayed on a laptop screen. The presentations were led by the pastoralists and allowed us to learn about their environmental concerns through their eyes. It was followed by a discussion of possibilities of, and interest in, systematically collecting and disseminating locally relevant degradation indicators as well as an 
assessment of the mobile technology currently available to pastoralists. All meetings were facilitated by our local facilitators in the pulaar language spoken in the region.

\subsection{Degradation indicators}

Since one goal of our pilot study was to come up with locally relevant indicators of degradation, much of the focus group discussions were centered on the topic of pasture quality and its characteristics and determinants. A simple question about different types of pastures and which pastures are good, bad, or worsening provided an entry point, and a "how do you know?" then prompted a conversation about indicators.

From the perspective of the pastoralists, indicators of pasture quality are in the first place related to livestock performance, rather than environmental markers. Thus, the quantity and quality of the milk (e.g., smell, taste), as well as the appearance of the skin or fur of the animals all were mentioned as indicators of pasture quality. While highly relevant to pastoralists from an economic or livelihood perspective, these indicators are arguably difficult to monitor and map. Only when directly asked about ways to tell whether a pasture is good or bad before leading the animals on it did the pastoralists produce the kind of environmental indicators that we had been expecting. And these were the indicators, and broader environmental concerns, that the pastoralists documented in the photo elicitation exercise, including a loss of forage quantity as well as quality of the vegetation cover.

More specifically, pastoralists noticed a decrease of tree cover over the years, which they attribute to a combination of precipitation shortfalls, pests and cutting. They are particularly concerned about a lack of natural regeneration of the semi-evergreen Sahelian native Guiera senegalensis, which leaves open spaces when mature trees die or are cut down (Figure 2a). This observation is in line with ethnobotanical and size class distribution studies from the larger Sahelian region, which have documented inhibited regeneration of some woody species (Sop et al., 2011).

A decrease in the diversity of tree species was also reported, especially around the seasonal ponds forming in depressions ("mares"), where dense stands of tamarind, baobab and other trees used to be found. The pastoralists attribute this to a lack of water in the depressions. Good rainy seasons occur only once every 3-4 years, and the surface water that seasonally inundates the depression now lasts shorter than it used to in the past (Figure $2 b$ ).

Not only trees, but also the herbaceous vegetation cover has become less dense in places. As a result, sand dunes formerly stabilized by vegetation have become mobile (Figure $2 \mathrm{c}$ ). And where the grass cover is still dense, some of it is reportedly due to the proliferation of an invasive grass species, which they call "demba yabal" (red grass) and which most likely belongs to the Rubiaceae family (Figure $2 \mathrm{~d}$ ). Its provenance disputed, the grass has started appearing in the area a few years ago and has expanded very quickly, outcompeting native species such as Zornia glochidiata, Schoenefeldia gracilis, Eragrostis tremula, and others. According to the pastoralists, the red grass is not palatable to the livestock, especially cattle. Sheep can digest it only when it is dry. Pastoralists therefore avoid pastures taken over by the grass. Invasive species research is indeed a topic that is thought to benefit from integrating local pastoral knowledge, as also shown at the 
example of the discovery of an invasive rubber vine (Cryptostegia grandiflora) in northeastern Ethiopia previously unknown to researchers and others working in the region (Luizza et al., 2016).

Of the indicators brought up by the local populations, most are not directly related to bioproductivity or the remote sensing-based Normalized Difference Vegetation Index (NDVI). It is therefore not surprising that NDVI-based metrics of land degradation fall short of (fully) characterizing degradation. Some of the local indicators were brought up in all three sites, whereas others were mentioned in one or two sites only (Table 1). The most prevalent degradation concerns across all sites were a loss of trees, be it through climate-induced mortality or cutting, as well as the proliferation of the invasive red grass. The latter was particularly concerning because of the speed at which it appears to be progressing. The prevalence of some other indicators was more site-dependent; for example, sandification is an issue in the northern sandy pastoral region (Yangyang) with its undulating sandy soils, whereas gully erosion occurs more commonly in the lateritic soils of the ferruginous pastoral region (Dodji).

\section{Potential for more systematic knowledge co-production}

Could the pastoralists' knowledge based on their regular field observations be harnessed in order to advance our understanding of land degradation and to inform decision making for sustainable land management? Involving citizens in science observations has seen an upsurge in the past decade with the growth of Web 2.0, cloud computing and collaborative cyberinfrastructure. This has also impacted the creation of geographic knowledge, allowing the acquisition of detailed geographic data at very low cost (Sui et al., 2013; Rossiter, 2015). The bulk of geocoded data some volunteered by citizen scientists, some involuntarily contributed by information-sensing mobile devices - originates in the developed world. However, public participation in environmental research has drawn interest also in the developing world with the goals of improving both the data base available to scientists and the lives and livelihoods of agricultural societies (Hoedjes, 2014). With the widespread use of cell phones, and increasingly smart phones, as well as rapid improvements in mobile network coverage, crowdsourcing of citizen science observations is becoming increasingly possible also in sub-Saharan Africa (Perkins, 2013).

In our pilot study, we explored the potential for more systematic co-production of knowledge on land degradation by assessing local pastoralists' interest in this endeavor, the mobile technology already available to them, and suitable incentives to motivate their participation. The participants in two of the three sites expressed an interest in assisting in a project assessing land condition that would involve knowledge sharing. In terms of available technology, they mostly possess simple cell phones that they use mainly for calling, but they currently have very limited access to the internet. However, according to one of our facilitators, a project by the Food and Agriculture Organization of the United Nations (FAO) is underway in one of the sites (Barkedji) to provide solar powered internet in the near future. Only the younger generation is familiar with and uses new technologies such as social media, thus the participants would expect to receive some training as well as the necessary technology for participating in a crowd-sourcing project. Obstacles expressed were time constraints, and costs associated with mobile data sharing. 
In order for systematic knowledge-coproduction to be successful and sustainable, there should be enough incentives for local land users to share their knowledge (Reed et al., 2013). Beyond reimbursement of any costs associated with the project, and financial incentives such as extra phone credit, a two-way exchange of knowledge, in which participants are in turn provided with an augmented form of the data they share as well as with remote sensing products showing pasture productivity, would be imperative. The participants unequivocally expressed their hope to in turn receive information that would help them in better managing livestock movement, or to attract future projects that address their environmental concerns. The issue of data confidentiality would have to be explored with participants, as the location of healthy and degraded pastures is knowledge that pastoralists might be willing to share within some subgroups but not others, which would require a setup that enables selective sharing.

\section{Conclusions}

In this qualitative pilot study in the Senegalese Ferlo, we assessed local perspectives and knowledge of rangeland degradation, and their potential for being harnessed more systematically. Land degradation is of concern to local pastoralist populations primarily because of its impact on livestock production, and this perspective is reflected in their ways of identifying and characterizing degradation. Overall bioproductivity is but one aspect of rangeland health. Other aspects include the composition and quality of the herbaceous and woody vegetation, which is where remote sensing has so far fallen short of providing locally relevant assessments (Fig. 3).

Local populations are keen observers of their environment, especially of the aspects directly related to their livelihoods. As the ultimate beneficiaries of many actions and interventions devised to address and reverse land degradation, local land users should have their voice heard in the definition, assessment and monitoring of land degradation. This pilot study has shown the potential of local pastoralist knowledge to contribute to our understanding of land degradation. While not all degradation indicators brought up by local pastoralists are easily measurable, let alone mappable, some - like for example the proliferation of invasive species - lend themselves to a more systematic collection at a larger scale with the help of a spatially explicit crowdsourcing platform. Such an effort could produce the much needed geospatial ground reference dataset with a two-fold utility: to serve as a decision support tool to local land managers, and to guide science to better understand land degradation and to develop more locally relevant remote sensing metrics, thus linking the research and development agendas.

\section{References:}


Bai, Z. G., Dent, D. L., Olsson, L., \& Schaepman, M. E. (2008). Global assessment of land degradation and improvement: 1. identification by remote sensing (No. 5). ISRIC-World Soil Information.

Behnke, R., \& Mortimore, M. (2016). The End of Desertification. Disputing Environmental Change. Springer.

Berkes, F. (2017). Environmental Governance for the Anthropocene? Social-Ecological Systems, Resilience, and Collaborative Learning. Sustainability, 9(7), 1232.

Brandt, M., Mbow, C., Diouf, A. A., Verger, A., Samimi, C., \& Fensholt, R. (2015). Ground-and satellite-based evidence of the biophysical mechanisms behind the greening Sahel. Global change biology, 21(4), 1610-1620.

Chambers, R. (1994). Participatory rural appraisal (PRA): Challenges, potentials and paradigm. World Development, 22, 1437-1454.

Cherlet, M., Reynolds, J., Hutchinson, C., Hill, J., von Maltitz, G., Sommer, S., Fensholt, R., Horion, S., Shepherd, G., Weynants, M., Kutnjak, H. \& Smid, M. (2018). World Atlas of Desertification $3^{\text {rd }}$ edition. Soon accessible: http://wad.jrc.ec.europa.eu/

Chouinard, J. A., \& Milley, P. (2018). Uncovering the mysteries of inclusion: Empirical and methodological possibilities in participatory evaluation in an international context. Evaluation and program planning, 67, 70-78.

Collier, J. (1957). Photography in anthropology: a report on two experiments. American anthropologist, 59(5), 843-859.

Collier, J., \& Collier, M. (1986). Visual anthropology: Photography as a research method. UNM Press.

Diouf, A. A., Brandt, M., Verger, A., Jarroudi, M. E., Djaby, B., Fensholt, R., Ndione, J.A. \& Tychon, B. (2015). Fodder biomass monitoring in Sahelian rangelands using phenological metrics from FAPAR time series. Remote sensing, 7(7), 9122-9148.

Enquist, C. A., Jackson, S. T., Garfin, G. M., Davis, F. W., Gerber, L. R., Littell, J. A., ... \& Hiers, J. K. (2017). Foundations of translational ecology. Frontiers in Ecology and the Environment, 15(10), 541-550.

Herrmann, S. M., Anyamba, A., \& Tucker, C. J. (2005). Recent trends in vegetation dynamics in the African Sahel and their relationship to climate. Global Environmental Change, 15(4), 394404.

Gadamus, L., Raymond-Yakoubian, J., Ashenfelter, R., Ahmasuk, A., Metcalf, V., \& Noongwook, G. (2015). Building an indigenous evidence-base for tribally-led habitat conservation policies. Marine Policy, 62, 116-124. 
GEF IEO (Global Environmental Facility Independent Evaluation Office) (2016). Value for Money Analysis for the Land Degradation Projects of the GEF. Document number: GEF/ME/C.51/Inf.02

Herrmann, S. M., \& Hutchinson, C. F. (2005). The changing contexts of the desertification debate. Journal of Arid Environments, 63(3), 538-555.

Herrmann, S., Sall, I., \& Sy, O. (2014). People and pixels in the Sahel: a study linking coarseresolution remote sensing observations to land users' perceptions of their changing environment in Senegal. Ecology and Society, 19(3).

Herrmann, S. M., \& Sop, T. K. (2016). The map is not the territory: How satellite remote sensing and ground evidence have re-shaped the image of Sahelian desertification. In The End of Desertification? (pp. 117-145). Springer, Berlin, Heidelberg.

Hoedjes, J. C. B. (2014). Public participation in environmental research. Occasional Paper, 22. Nairobi: World Agroforestry Center.

Hutchinson, C. F., Herrmann, S. M., Maukonen, T., \& Weber, J. (2005). Introduction: the "greening" of the Sahel. Journal of Arid Environments, 63, 535-537.

Kong, T. M., Kellner, K., Austin, D. E., Els, Y., \& Orr, B. J. (2015). Enhancing participatory evaluation of land management through photo elicitation and photovoice. Society \& Natural Resources, 28(2), 212-229.

Middleton, N. J., \& Thomas, D. S. (1992). World atlas of desertification.

Luizza, M., Wakie, T., Evangelista, P., \& Jarnevich, C. (2016). Integrating local pastoral knowledge, participatory mapping, and species distribution modeling for risk assessment of invasive rubber vine (Cryptostegia grandiflora) in Ethiopia's Afar region. Ecology and Society, 21(1).

Mortimore, M. (1989). Adapting to drought: Farmers, famines and desertification in West Africa. Cambridge University Press.

Myneni, R. B., Hall, F. G., Sellers, P. J., \& Marshak, A. L. (1995). The interpretation of spectral vegetation indexes. IEEE Transactions on Geoscience and Remote Sensing, 33(2), 481-486.

Nakashima D. (2015). Local and indigenous knowledge at the science-policy interface. Pages 15-18 in UNESCO science report: towards 2030.

Niamir-Fuller, M. (1998). The resilience of pastoral herding in Sahelian Africa. in F. Berkes and C. Folke, editors. Linking social and ecological systems: management practices and social mechanisms for building resilience. Pages 250-284 Cambridge University Press, Cambridge, UK. 
Oba, G. (2012). Harnessing pastoralists' indigenous knowledge for rangeland management: three African case studies. Pastoralism: Research, Policy and Practice, 2(1), 1.

Oldeman, L.R., Hakkeling, R.T.A. \& Sombroek, W.G. (1991). World Map of the Status of Human-induced Soil Degradation: An Explanatory Note, second revised edition. ISRIC/UNEP.

Olsson, L., Eklundh, L., \& Ardö, J. (2005). A recent greening of the Sahel-trends, patterns and potential causes. Journal of Arid Environments, 63(3), 556-566.

Perkins, N.I. 2013: Realising the Potential of Citizen Science. SciDev.Net http://www.scidev.net/global/communication/editorials/realising-the-potential-of-citizenscience.html

Reed, M. S., Fazey, I., Stringer, L. C., Raymond, C. M., Akhtar-Schuster, M., Begni, G., ... \& Buckmaster, S. (2013). Knowledge management for land degradation monitoring and assessment: an analysis of contemporary thinking. Land Degradation \& Development, 24(4), 307-322.

Rossiter, D. G., Liu, J., Carlisle, S., \& Zhu, A. X. (2015). Can citizen science assist digital soil mapping?. Geoderma, 259, 71-80.

Sonneveld, B. G., \& Dent, D. L. (2009). How good is GLASOD?. Journal of Environmental Management, 90(1), 274-283.

Sop, T. K., Oldeland, J., Schmiedel, U., Ouedraogo, I., \& Thiombiano, A. (2011). Population structure of three woody species in four ethnic domains of the sub-sahel of Burkina Faso. Land Degradation \& Development, 22(6), 519-529.

Sui, D., Elwood, S., \& Goodchild, M. (Eds.). (2013). Crowdsourcing geographic knowledge: volunteered geographic information (VGI) in theory and practice. Springer Science \& Business Media.

Tappan, G. G., Sall, M., Wood, E. C., \& Cushing, M. (2004). Ecoregions and land cover trends in Senegal. Journal of arid environments, 59(3), 427-462.

Thomas, D. S., \& Middleton, N. J. (1994). Desertification: exploding the myth. John Wiley and Sons.

Tucker, C. J., Dregne, H. E., \& Newcomb, W. W. (1991). Expansion and contraction of the Sahara Desert from 1980 to 1990. Science, 253(5017), 299-300.

UNEP (2016) Framework and Guiding Principles for a Land Degradation Indicator. Draft for Consultation. 
Warren, A. (2002). Land Degradation is Contextual. Land Degradation and Development, 13, 449-459. doi:

Woods, S. R., \& Ruyle, G. B. (2015). Informal rangeland monitoring and its importance to conservation in a US ranching community. Rangeland Ecology and Management, 68(5), 390401.

Yengoh, G. T., Dent, D., Olsson, L., Tengberg, A. E., \& Tucker III, C. J. (2015). Use of the Normalized Difference Vegetation Index (NDVI) to Assess Land Degradation at Multiple Scales: Current Status, Future Trends, and Practical Considerations. Springer. 